\title{
Teaching Practice in UK ELT Master's Programmes
}

Ifigenia Papageorgiou, City Unity College, Athens, Greece

Fiona Copland, University of Stirling, Stirling, Scotland

Vander Viana, University of Stirling, Stirling, Scotland

David Bowker, University of Stirling, Stirling, Scotland

Edward Moran, University of Stirling, Stirling, Scotland

This is a pre-copyedited, author-produced PDF of an article accepted for publication in ELT Journal following peer review. The version of record Ifigenia Papageorgiou, Fiona Copland, Vander Viana, David Bowker, Edward Moran, Teaching practice in UK ELT Master's programmes, ELT Journal, Volume 73, Issue 2, April 2019, Pages 154-165, is available online at: https://doi.org/10.1093/elt/ccy050 


\section{Teaching Practice in UK ELT Master's Programmes}

\section{Abstract}

3 Despite the fact that UK ELT Master's programmes are numerous, diverse and financially 4 important, very little research has been conducted on whether they deliver teaching practice 5 (TP) or micro-teaching (MT) and on what students' expectations of these modules are. The 6 present paper addresses this gap by examining how many ELT-related Master's programmes 7 in the UK offer TP/MT modules and by investigating students' expectations of these modules.

8 Drawing on data from document analysis, we show that only 34 out of the 141 UK ELT-related 9 Master's programmes offer a TP module and 12 offer an MT module. Data from pre-/poststudy questionnaires and focus groups indicate that students consider practical teaching experience an important part of their programmes and report that they would like more course time to be spent on it. Based on these findings, we recommend that UK ELT Master's programmes should provide students with ways to gain such practical experience.

\section{Introduction}

A recent audit has revealed that there are 141 ELT-related Master's programmes offered by different institutions across the UK (Author et al. 2017). Undoubtedly, home and international students attending these Master's programmes constitute an important source of income for UK Higher Institutions but also for the UK as a whole. Despite the fact that UK ELT Master's programmes are numerous, diverse and financially important, very little research has been conducted into ELT Master's students' expectations of their programmes and whether these expectations are met. Neither is there research on what Master's students would like to see included in an ELT programme. This is surprising since such information would be invaluable in a number of areas of UK higher education - from programme design to marketing - and would help institutions enhance the student experience. The academic research reported on in 
1 this article addresses this gap with regard to students' expectations concerning practical

2 teaching experience and examines whether or not these expectations are met.

Practical teaching experience can be provided in a range of ways in ELT Master's programs: from teaching practice $(\mathrm{TP})$ to teaching peers in simulated classrooms - usually called microteaching (MT). Some programmes combine both approaches or include classroom observation or placements in their modules.

TP is important as many students enrol on ELT Master's programmes expecting to develop their practical skills (Co-author et al. 2017); indeed, some employers also expect graduates of Master's programmes to have both theoretical knowledge and practical experience. This is in part because the majority of programmes now accept students with no teaching experience (this is in contrast to a time when Master's programmes were exclusively designed for experienced teachers). In terms of learning outcomes, the promises made by Universities vary. For instance, programs which are aimed at novices and include TP ask students "to use the concepts and theories that you [they] encounter during your [their] course of study in your [their] own classroom" (MA TESOL, University of Birmingham). On the other hand, other programs which are targeted at experienced teachers and do not include TP promise to help students:

- “develop advanced knowledge of TESOL-related research, theory and areas of debate

- understand more deeply your [their] role as TESOL practitioner given the international currency of English and the developments in the educational environment afforded by technology access and global networking

- develop advanced professional skills such as conducting needs analyses and evaluating,

3 adapting and designing teaching and learning resources

- develop academic literacy." (MA TESOL, University of Manchester). 
2 project (Co-author et al. 2017). One of the aims of this project was to conduct an audit of all

3 ELT-related Master's offered throughout the UK. The audit expands and enhances the

4 guidance available in other sources such as the EL Gazette, providing comprehensive and 5 detailed information. In addition, the project also investigated ELT Master's students' desires

6 and expectations in these programmes. In this paper, we draw on the project's data sets to focus

7 specifically on the topic of practical teaching experience by exploring how many UK ELT-

8 related Master's programmes offer TP/MT modules and investigating students' expectations

9 of these modules.

The paper is structured as follows. We first contextualize the present study by reviewing the literature pertinent to our topic. Next, we briefly describe the methods used for data collection. Then, we present our results from the audit and the two different research instruments before discussing our results. We conclude with suggestions for UK universities that offer ELT Master's.

\section{Literature Review}

17 In this section, we review studies that have investigated students' views and perceptions of ELT Master's programmes in English-speaking countries with a focus on the UK. Although there is a good deal of research on study abroad in general (see, for example, Fang et al. 2015, Chang and Strauss 2010), there is little research on students' experiences and views of ELTrelated Master's programmes. The studies that have been undertaken focus on preparation and programme quality.

Research on preparation is sparse although many students spend time and money getting ready for their study abroad experience. Schartner and Young's (2015) study bucks 
1 this trend. They explored the early sojourn views and experiences of non-UK postgraduate

2 students attending a Master's in Cross Cultural Communication or in Applied Linguistics and

3 TESOL at a UK university. Their main findings were that pre-departure knowledge about the

4 host country and students' autonomy in the decision to study abroad have a positive impact on

5 the levels of satisfaction at the early stages of the study-abroad experience.

There is slightly more interest in programme quality in the literature. In the New Zealand context, a study examined the expectations of TESOL Master's students of Asian background ( $\mathrm{Li}$ and Tin 2013). With regard to mismatches, Li and Tin stress the fact that the most serious misalliance between students' own expectations and the reality of the programme was the lack of TP in the Master's (Li and Tin ibid: 32). This finding has clear relevance to the project we report on here.

In the UK, Fordyce and Hennebry (2013) researched the perceptions and expectations of international TESOL Master's students. Their results show that Chinese students were more content with the programme as compared to their non-Chinese classmates. However, like the students in Li and Tin's (2013) study, they were less satisfied with the practical aspects of the programme.

Finally, in the UK, a study examined the perceptions of students who had completed either an on-campus or an online TESOL Master's (Co-Author and collaborator, 2012). The research revealed that the major difference between the two groups was in the area of research skills, that is, the online students had participated in more research activities as compared to their on-campus colleagues (Co-Author and collaborator ibid: 73).

As the discussion above shows, some research has been conducted on (international) students' perceptions of ELT Master's in some parts of the world. In the UK, however, this type of research is limited. The few studies we have been able to identify (Co-Author and 
1 collaborator 2012; Fordyce and Hennebry 2013; Schartner and Young 2015) focus on single

2 institutions. Two of these studies touched on TP and suggest that there is a mismatch between

3 students' expectations (or desires) and the reality of their programmes.

\section{Methods}

5 To address the issue under investigation, we draw on data from four different sources: (a) an

6 audit of UK ELT Master's programmes; (b) a pre-study questionnaire; (c) a post-study

7 questionnaire and (d) 11 focus group interviews with home and international ELT Master's

8 students in the UK. Data were collected between September 2015 and September 2016.

In total, the questionnaires were completed by 502 (pre-study) and 346 (post-study) participants, who were undertaking their ELT Master's in the UK at the time. Focus groups were conducted in 11 UK Higher Education Institutions by five members of the project team (see Appendix 1 for a description of the focus groups).

Given the focus of the article, participants' teaching experience is an important matter.

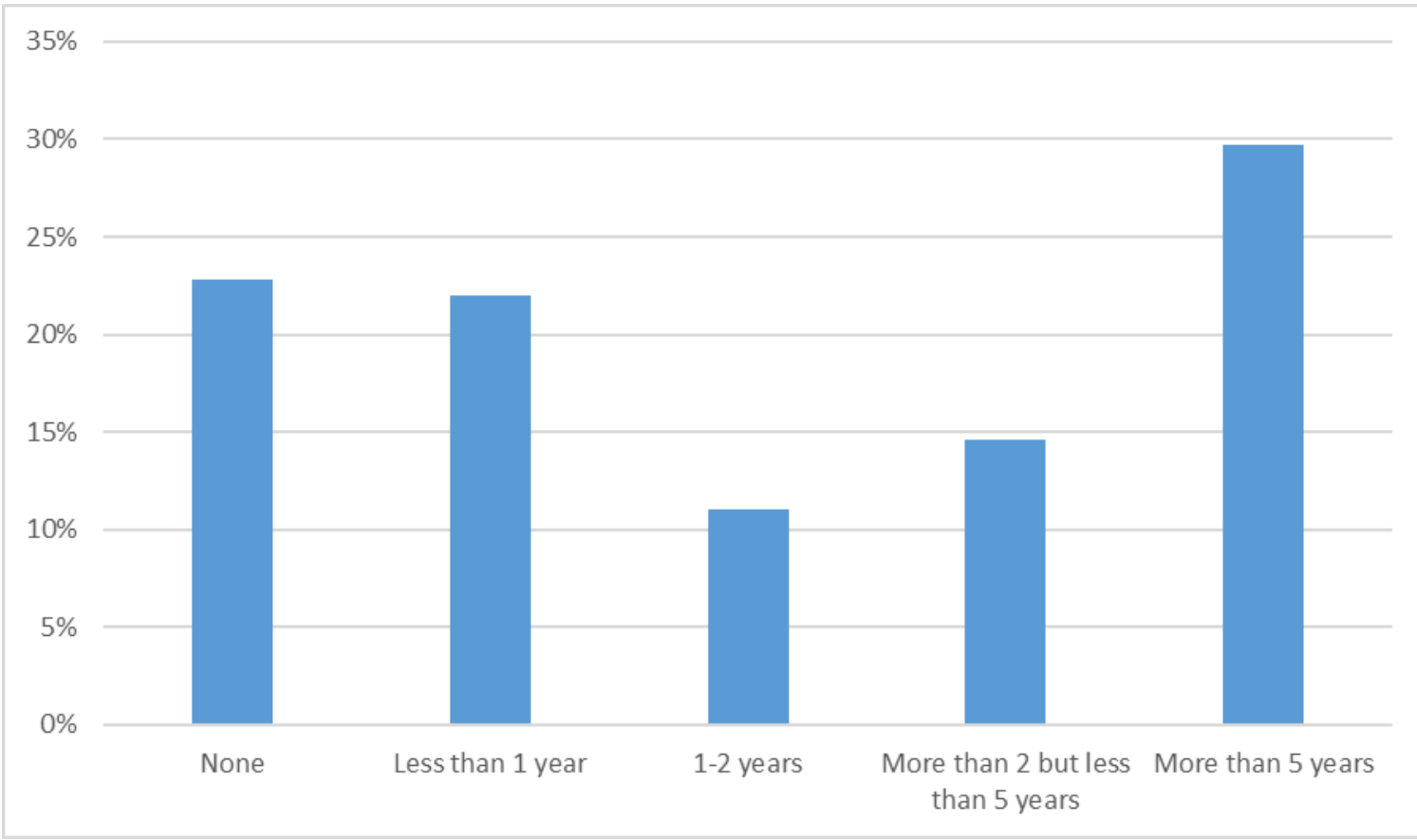




\section{Figure 1: Teaching experience as reported by the pre-study questionnaire respondents}

2 As can be seen, a small majority of students had little experience: in the pre-study 3 questionnaire, around $23 \%$ had no experience at all while $33 \%$ had taught for up to two years.

4 In contrast, nearly $30 \%$ of respondents had more than five years' experience.

\section{$6 \quad$ Findings}

\section{Audit Findings}

8 With regard to our question of how many UK-based ELT-related Master's programmes offer 9 a TP or MT module, our results show that only 34 (out of the 141 Master's programmes that 10 we have been able to identify) have a TP module (teaching genuine students) and 12 (out of the 141) have a MT (teaching their peers) module. The TP modules we surveyed differ in format and length. For example, students at the University of Ulster can undertake an eightweek Erasmus-funded teaching practice placement in Hungary while those at Sheffield Hallam University have to complete six hours of supervised teaching practice for the Trinity College Certificate in TESOL, which has been integrated into their Master's programme. Although MT may be a popular way to prepare students for the classroom since it is easier to organise than

$17 \mathrm{TP}$, it is interesting that only 12 programmes explicitly include a MT module. However, it could be that modules called 'teaching practice' include microteaching, or are wholly microteaching. 
1 Figures 2 and 3 show the results of the pre-study and post-study questionnaires, respectively.

2 In both, students were asked to choose eight modules (among 31 different options) to be

3 included in an ideal ELT Master's. The results show TP (rather than MT, which was also an

4 option in the questionnaires) was chosen as one of the eight modules to be included: both at

5 the beginning and towards the end of their studies, participants recognised the value of the TP

6 component.

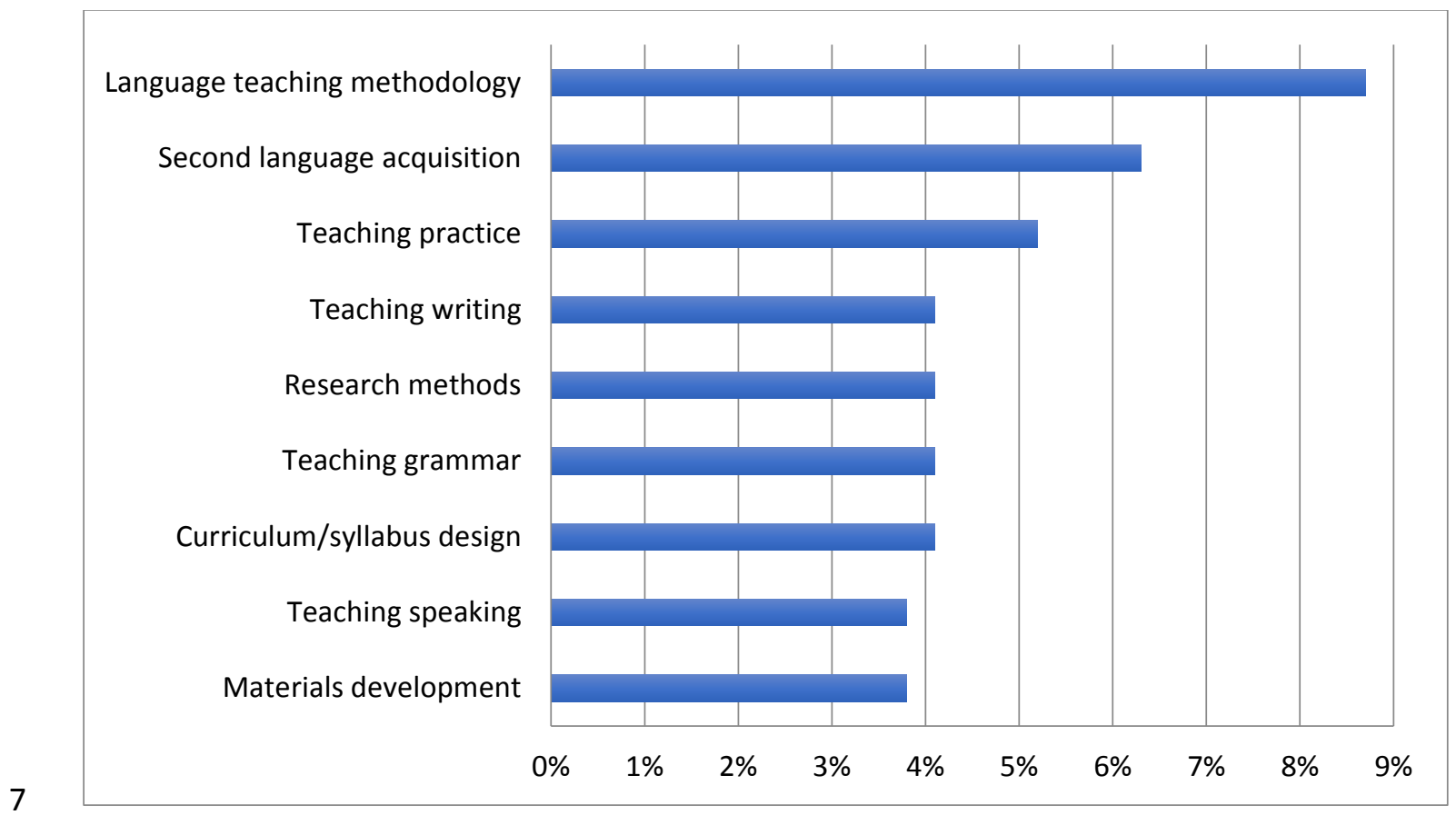

$8 \quad$ Figure 2: ELT Master's students' pre-study choice of modules (chosen among 31) 
1
Language teaching methodology

Second language acquisition

Materials development

Curriculum/syllabus design Assessment/testing

Teaching practice

Research methods

Teacher education/training

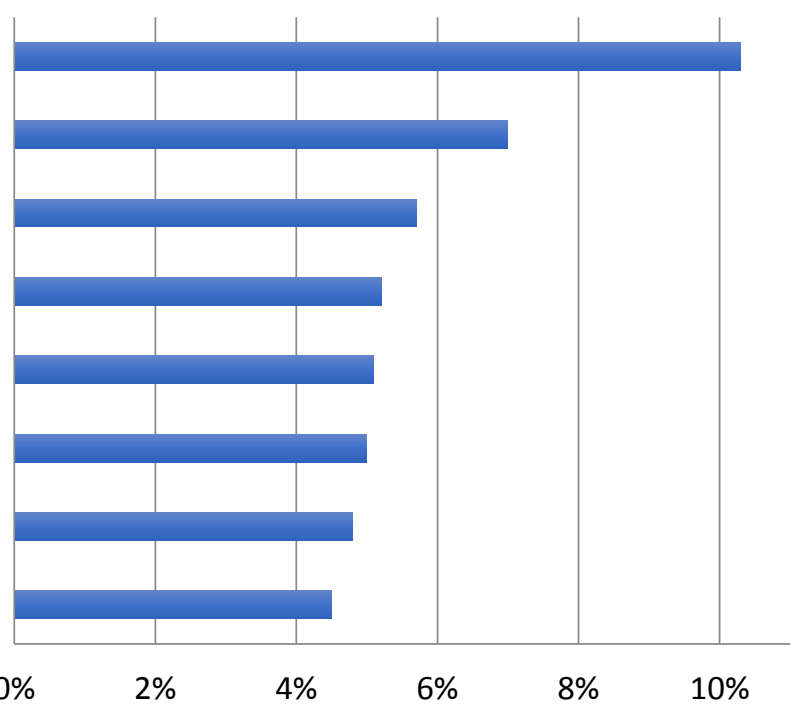

\section{Figure 3: ELT Master's students' post-study choice of modules (chosen among 31)}

The pre- and post-study questionnaire results are in line with the focus group data results. In one of the focus group tasks, participants were asked to select six modules (out of 15 options) that they thought should definitely be included on an ideal ELT Master's programme. The results show that, in the vast majority of the focus groups, a module called 'practice in teaching', which would correspond to TP and/or MT, was selected. A number of students commented on the importance of both TP and MT. For instance, a home student explained that:

If we all go out and go and teach real people, then it's real teaching practice but before you get there, it's good to try things out on yourselves. Micro-teaching has its benefits but definitely at the end of all this, if we all stand up in front of a real class and do real time practice, to be prepared, at least be semi-prepared for what's to come next I think is key. Both are key. (10, Scotland $\left.{ }^{1}\right)$.

\footnotetext{
${ }^{1}$ The number identifies our focus groups (see Appendix 1), and the country indicates the participant's nationality.
} 
1 This view was echoed by an international student who suggested that the two can be introduced 2 incrementally:

I think it's step by step. At the very beginning, you need to practice with your classmates and you can get more skills and then you put your... skills into the real teaching practice, just step by step (11, China).

Another student also saw MT as a kind of preparation for TP and highlighted the value of the video recording in MT:

Ifeel like the microteaching is a stepping stone to actual teaching practice. I feel like they're both relevant, ...... like we had the video recorder, we watched ourselves back, we reflected on it, brought in the whole reflective practice, and that was useful for people that hadn't seen themselves teaching before, and you could pinpoint things that you yourself needed to work on individually, which set you up for actual teaching practice then ... I think the two of them go hand in hand (2, Ireland).

Rather than splitting TP and MT into two modules, one student suggested they be merged: Maybe at first we learn how ... we do observation in the beginning of the module and then we do micro-teaching and then we got like hands-on teaching, real teaching practice. That would be ... Yeah, in one module. It could be done in one module (6, Taiwan).

\section{Teaching Practice as a Mode of Delivery in an ELT Master's}

Moving on to modes of delivery, Figure 4 shows how much of their time students perceived to have spent on each of the modes of delivery provided (actual) and how much they would have preferred to spend on each of them (desired). The seven delivery modes specified in Figure 4 
1 were rated on a five-point scale from 'none' to 'all'. With regard to TP, there are two interesting

2 points. Firstly, participants would like to have had more course time compared to what was

3 offered on their programme ('actual' TP versus 'desired' TP). Secondly, the participants would

4 also have liked more time spent on teaching observations, which research has shown can

5 support teachers in learning to teach (O’Leary 2017). Nonetheless, TP was still more popular

6 than teaching observations.

Independent study

Lectures

Seminars/workshops

E-learning

One-to-one tutorials

Teaching practice

Teaching observations

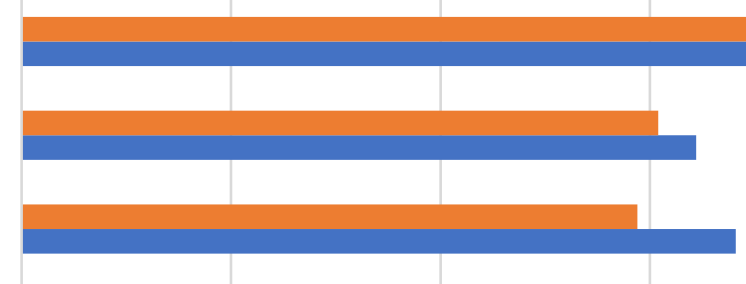

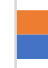

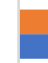

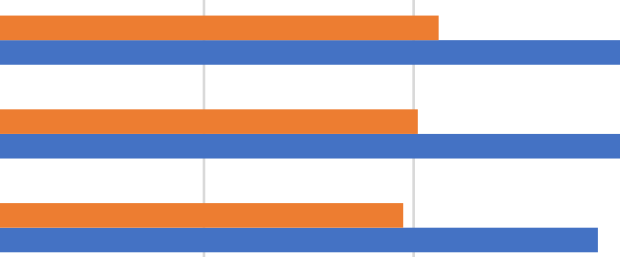

0

1

2

3

4

5

- Actual Desired

Figure 4: ELT Master's students' post-study delivery modes

11 In focus groups, participants were asked to indicate: (a) what percentage of their course time was actually spent on the delivery modes shown in Figure 4 and (b) what percentage of their course time they would like to spend on these delivery modes. The results for TP are given in Figure 5. All focus groups indicated that they wanted a greater percentage of their course time spent on TP. Even those participants (Focus Group 2) who had had the highest amount of TP 
1 time (i.e. $30 \%$ of their course time) said they would have liked slightly more (35\%). In three

2 focus groups, TP was not identified as an 'actual' study mode, but the student participants from

3 these institutions (Focus Groups 7, 8, and 9) all indicated that they would have welcomed it to

4 some extent.

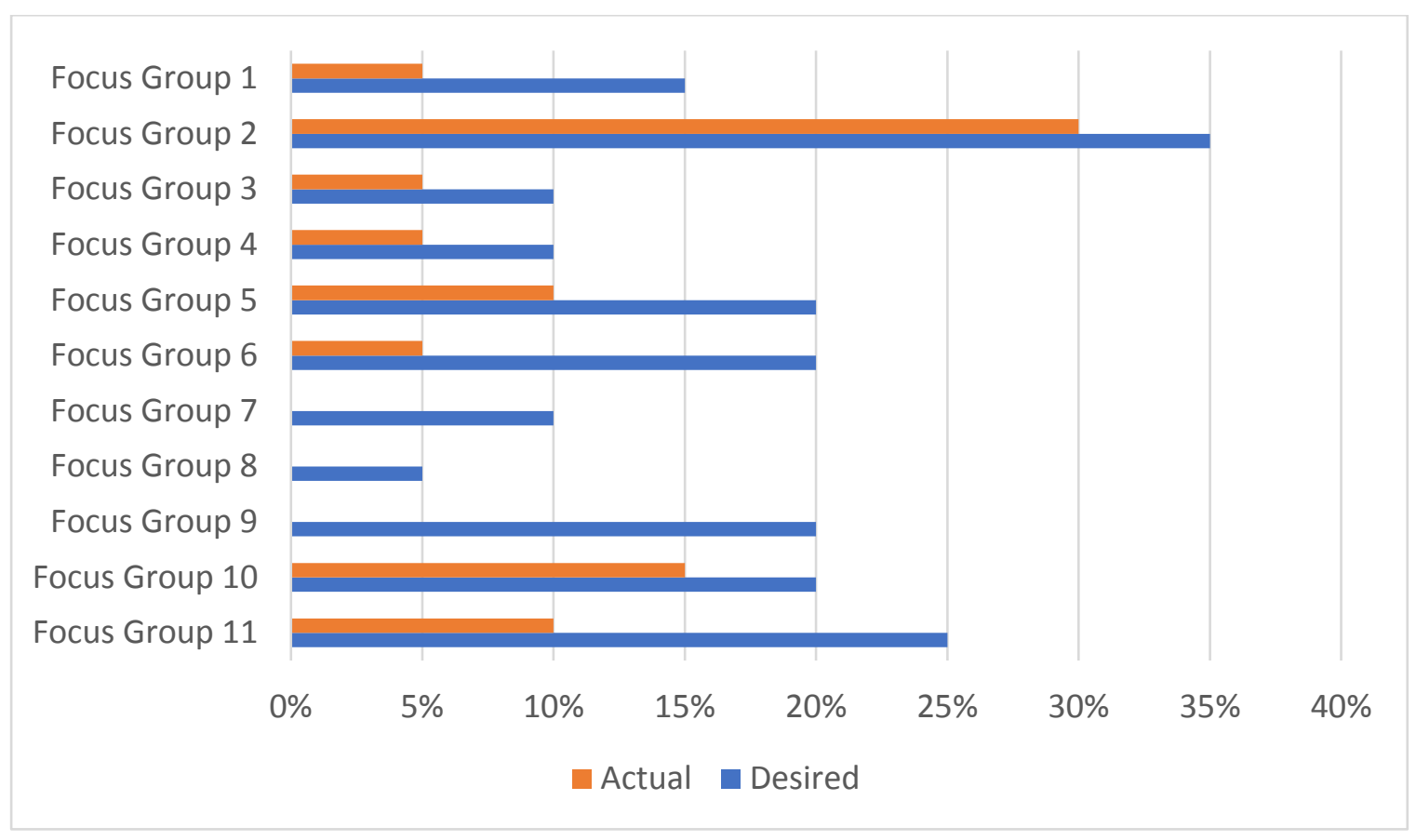

6 Figure 5: Teaching practice as a study mode type

8 In the focus groups, various reasons were given for considering TP important in an ideal

9 Master's. One participant mentioned putting theoretical knowledge into practice, gaining in10 depth knowledge and making connections with reality:

I expect like $30 \%$ of the practice into our programme because when we put our knowledge into the practice, we know what's going on, what's actually going on with the knowledge. So actually it can help us to know more in depth of our knowledge so that we can know how to deal with different situations in our real life. So that's why I think it's important and it's necessary (11, China). 
1 Another student stressed the importance of the authentic opportunity that TP offers:

On the real-life experience opportunity, another UK student said that TP is important because: ...you can't really know how to be a teacher until you've had that moment of standing in front of the people who expect you to be a teacher. (9, UK).

Another student explained her choice on the basis of employability. She made reference to the Certificate in English Language Teaching to Adults (CELTA), a qualification that is trusted by employers, language schools and governments around the world and which has a sizeable observation and TP component.

I started to look for jobs here [...] And one lady was very nice, she replied, 'I'm not completely sure but I'm gonna check if you don't need a CELTA and if we can hire you with your experience, your previous qualification and the masters that you are doing.' And she said, 'Unfortunately we cannot hire you because your Master's programme, even though it's English language teaching, doesn't have at least six hours of supervised teaching.... So, yeah, I think this programme should include at least ... a $5 \%$ work thing, to have some teaching experience with somebody watching you and taking notes and giving you advice would be good (8, Chile).

\section{Students' perceptions of pros and cons of TP and MT}


1 The focus group data revealed both positive and negative perceptions about TP and MT. For

$2 \mathrm{TP}$, the main advantages cited were that both the experience and the assessment were

3 considered more realistic. In addition, students said that it was useful practice for

4 inexperienced teachers and that teaching students from backgrounds different to those at

5 home was valuable. However, there were also problems: students noted that they were

6 restricted in what they could teach and that there was sometimes no consistency in the

7 students who attended the classes. The fact that students were different from those at home

8 could also be considered a disadvantage.

Students noted a number of advantages for MT. Some focused on classmates, who were able to give useful feedback and model creative ideas. Students also noted that MT provided the opportunity to learn about lesson planning, teacher presence and classroom atmosphere. On the negative side, students found that the classroom environment was not realistic as peers were 'too nice' or their language level was too high.

\section{Discussion}

Our audit results show that only very few UK ELT-related programmes offer TP/MT modules. In contrast, our questionnaire and focus group data show that most student participants expect a TP/MT component in their ELT Master's. Furthermore, whether or not they experienced TP as a study mode in their Master's, students would have liked more (Figures 4 and 5). The expectations of students on UK ELT Master's programs are similar to those of Asian ELT Master's students in New Zealand investigated by Li and Tin (2013): both groups indicated their willingness to get involved in TP. Our results also reveal students' expectations that their ELT Master's programmes will not only provide theoretical knowledge about English language teaching but also experience of applying that knowledge to practice through TP/MT. 

module. They must either find institutions (e.g. state or private schools, language institutes or charity organizations/NGOs) that would be happy to cooperate in offering placements to

trainee ELT teachers or they must organise TP classes on their own premises, where recruiting students can be extremely difficult (as any CELTA course director will confirm). Even if cooperative institutions are happy to offer placements to students there is the issue of how long each placement needs to be so that it offers a substantial, supported teaching experience to each of the trainee teachers. Even students, who were generally supportive of TP modules commented in the focus groups on the difficulty of fitting TP into a one-year programme and the comparative feasibility of MT.

Designing the content of a TP module is another challenge, particularly if the students are novice teachers. How much teaching will students be able to do? What level will they teach (it is rare to find absolute beginners in the UK)? To what extent will TP provide a realistic experience, especially if students are from overseas where different educational norms pertain? Perhaps the thorniest issue is assessment. There is an incongruence between the academic level of a UK Master's programme and beginner teachers' classroom practice. Indeed, programmes such as the CELTA are deemed to be at Level 5 of the England and Wales qualifications framework while a Master's programme is at Level 7. Rather than assessing the quality of TP, course work built around it such as reflective essays, learner case studies and assignments focusing on course and materials design could be introduced. Students would then be able to develop their pedagogical practice in a safe environment without worrying about being graded on their teaching. This approach would also support Master's students in developing skills for Continuing Professional Development (CPD). The importance of the individual's commitment to CPD cannot be underestimated in ELT, and teachers are increasingly expected to engage with it, as evidenced by the British Council's CPD Framework for (Teachers 
1 https://www.teachingenglish.org.uk/sites/teacheng/files/CPD\%20framework\%20for\%20teach

2 ers_WEB.PDF). In addition to providing the opportunity to assess work at the correct level for

3 a Master's programme, this approach addresses another request from ELT Master's programs

4 - i.e. to be evaluated by means of pedagogical genres (see Co-Author et al. 2017).

5

The study also revealed that students are generally supportive of MT although, for some, this is a precursor to TP. However, little is known about the organisation of MT in different institutions. For example, how is preparation and assessment managed and how much teaching practice do students have? Furthermore, how can MT overcome the weaknesses that students identified, such as peers being too nice and having strong English proficiency? Introducing 'strategic mediation' (Johnson and Dellagnelo, 2014: 409) could be beneficial in this regard. Rather than waiting till the end of the MT session to discuss the lesson, the module leader and peers can halt the MT at any point to give suggestions, feedback or to ask questions. One advantage of this approach is that peers are engaged not only as 'pretend' students but also as co-learners and so are critically appraising the class. Johnson and Dellagnelo (2014) also suggest that strategic mediation can also be instrumental in assisting student teachers to reconceptualise their lessons based on the on-line responses by peers to the activities they have designed.

\section{Conclusion}

The data from pre- and post-study questionnaires as well as 11 focus groups conducted with home and international students show that many Master's students in the UK desire and expect a TP/MT component on their ELT programmes. The pre- and post-study questionnaire data also show a preference for TP (teaching genuine students) over MT (teaching peers). Moreover, in both the post-study questionnaire and the focus groups, our participants reported that they would like to have spent more course time on TP than what was offered on their Master's. 

meeting students' desires and expectations with regard to practical teaching experience. Although organizing a TP component and offering placements to ELT Master's students is not without its difficulties, the research suggests that they would enhance the experience of students and go some way towards meeting their desires and expectations. Furthermore, such a component would allow students to make connections between ELT theory and practice, to experiment with new ideas, and increase their employability.

\section{3,854 words excluding the abstract and the references}

\section{$9 \quad$ References}

Author et al. 2017.

Chang Ch.E. and Strauss P. 2010. 'Active Agents of Change?' Mandarin-Speaking Students in New Zealand and the Thesis Writing Process. Language and Education

Co-Author et al. 2017.

Co-Author and collaborator 2012.

Fang W., Clarke A. and Wei Y. 2015. Empty Success or Brilliant Failure: An Analysis of Chinese Students Study Abroad Experience in a Collaborative Master of Education Program. Journal of Studies in International Education: 1-24 available only online at http://jsi.sagepub.com.ezproxy.is.ed.ac.uk/content/early/2015/05/22/10283153155871 06.full.pdf+html accessed on 02/03/2016

Fordyce K. and Hennebry M. 2013. An Investigation to the Degree of Alignment between Student Expectations and Actual Experiences on a One-Year Masters in TESOL at a UK University. Paper Presented at the BAAL Conference, Edinburgh, 6/9/2013. 
1 Johnson, K. E. and Dallagnelo, A. K. (2014). How 'sign meaning develops': Strategic mediation in learning to teach. Language Teaching Research, 17/4, pp. 409-432.

Li B. and Tin T. B. 2013. Exploring the Expectations and Perceptions of Non-native English Speaking Students in Masters Level TESOL Programs New Zealand Studies in Applied Linguistics 19/2:21-35.

O’ Leary M. 2017. Reclaiming Lesson Observation: Supporting Excellence in Teacher Learning. Oxon: Routledge.

8 Schartner A. and Young T. 2015. "Culture Shock or Love at First Sight? Exploring the 'Honeymoon' Stage of the International Student Sojourn” in Fabricius A.H. and Preisler B. ed. Transcultural Interaction and Linguistic Diversity in Higher Education. Basingstoke, UK: Palgrave MacMillan: 12-33. 
$1 \quad$ Appendix 1

2 Table 1: Focus Groups

\begin{tabular}{|c|c|c|c|c|c|}
\hline $\begin{array}{l}\text { Focus } \\
\text { Group }\end{array}$ & Researcher & Date & University & Length & Participants \\
\hline 1 & A (Female) & 21 June 2016 & Scotland & $1: 35$ & $\begin{array}{l}\text { Sex: Female (4); } \\
\text { Male: (2) } \\
\text { Country: China } \\
\text { (5); South Korea: } \\
\text { (1) }\end{array}$ \\
\hline 2 & B (Male) & 23 June 2016 & $\begin{array}{l}\text { Northern } \\
\text { Ireland }\end{array}$ & $1: 50$ & $\begin{array}{l}\text { Sex: Female (2); } \\
\text { Male (3) } \\
\text { Country: Ireland } \\
\text { (2); Northern } \\
\text { Ireland (1); Saudi } \\
\text { Arabia (1); } \\
\text { United } \\
\text { States (1) }\end{array}$ \\
\hline 3 & $\mathrm{C}$ (Male) & 29 June 2016 & England & $2: 02$ & $\begin{array}{l}\text { Sex: Female (4); } \\
\text { Male (2) } \\
\text { Country: China } \\
\text { (4); UK (1); US } \\
\text { (1) }\end{array}$ \\
\hline 4 & $\mathrm{D}$ (Female) & 1 July 2016 & England & $1: 17$ & Sex: Female (4) \\
\hline
\end{tabular}




\begin{tabular}{|c|c|c|c|c|c|}
\hline & & & & & $\begin{array}{l}\text { Country: Brazil } \\
\text { (1); China (1); } \\
\text { Indonesia (1); } \\
\text { South Africa (1) }\end{array}$ \\
\hline 5 & $\mathrm{D}$ (Female) & 29 June 2016 & England & $1: 19$ & $\begin{array}{l}\text { Sex: Female (5); } \\
\text { Male (3) } \\
\text { Country: China } \\
\text { (1); UK (3); } \\
\text { Germany (1); } \\
\text { Greece (2); } \\
\text { Taiwan (1) }\end{array}$ \\
\hline 6 & $\mathrm{D}$ (Female) & 28 June 2016 & England & $1: 34$ & $\begin{array}{l}\text { Sex: Female (4); } \\
\text { Male (1) } \\
\text { Country: China } \\
\text { (2); Taiwan (1); } \\
\text { Japan (1); } \\
\text { Azerbaijan (1) }\end{array}$ \\
\hline 7 & $\begin{array}{l}\text { C (Male) } \\
\end{array}$ & 30 June 2016 & England & $1: 57$ & $\begin{array}{l}\text { Sex: Female (4); } \\
\text { Male: (2) } \\
\text { Country: Spain } \\
\text { (1); Japan (1); } \\
\text { China (1); Africa } \\
\text { (1); England (1); } \\
\text { German (1) }\end{array}$ \\
\hline
\end{tabular}




\begin{tabular}{|c|c|c|c|c|c|}
\hline 8 & C (Male) & 27 June 2016 & England & $1: 41$ & $\begin{array}{l}\text { Sex: Female (1); } \\
\text { Male (3) } \\
\text { Country: US (1); } \\
\text { UK (1); Palestine } \\
\text { (1); Chile (1) }\end{array}$ \\
\hline 9 & D (Female) & 24 June 2016 & England & $1: 10$ & $\begin{array}{l}\text { Sex: Female (7) } \\
\text { Country: China } \\
\text { (3); UK (2); Italy } \\
\text { (1); Vietnam (1) }\end{array}$ \\
\hline 10 & E (Male) & 29 June 2016 & Scotland & $1: 35$ & $\begin{array}{l}\text { Sex: Female (6); } \\
\text { Male (2) } \\
\text { Country: China } \\
\text { (5); Scotland (2); } \\
\text { Bangladesh (1) }\end{array}$ \\
\hline 11 & E (Male) & 4 July 2016 & England & $1: 31$ & $\begin{array}{l}\text { Sex: Female (8) } \\
\text { Country: China } \\
\text { (8) }\end{array}$ \\
\hline
\end{tabular}

